Article

\title{
A Rapid Process for Fabricating Gas Sensors
}

\section{Chun-Ching Hsiao * and Li-Siang Luo}

Department of Mechanical Design Engineering, National Formosa University, No. 64, Wunhua Rd., Huwei Township, Yunlin County 632, Taiwan; E-Mail: q14703@gmail.com

* Author to whom correspondence should be addressed; E-Mail: cchsiao@nfu.edu.tw;

Tel.: +886-5-6315-557; Fax: +886-5-6363-010.

Received: 4 June 2014; in revised form: 30 June 2014 / Accepted: 1 July 2014 /

Published: 9 July 2014

\begin{abstract}
Zinc oxide $(\mathrm{ZnO})$ is a low-toxicity and environmentally-friendly material applied on devices, sensors or actuators for "green" usage. A porous $\mathrm{ZnO}$ film deposited by a rapid process of aerosol deposition (AD) was employed as the gas-sensitive material in a $\mathrm{CO}$ gas sensor to reduce both manufacturing cost and time, and to further extend the AD application for a large-scale production. The relative resistance change $(\Delta \mathrm{R} / \mathrm{R})$ of the $\mathrm{ZnO}$ gas sensor was used for gas measurement. The fabricated $\mathrm{ZnO}$ gas sensors were measured with operating temperatures ranging from $110{ }^{\circ} \mathrm{C}$ to $180{ }^{\circ} \mathrm{C}$, and $\mathrm{CO}$ concentrations ranging from $100 \mathrm{ppm}$ to $1000 \mathrm{ppm}$. The sensitivity and the response time presented good performance at increasing operating temperatures and $\mathrm{CO}$ concentrations. $\mathrm{AD}$ was successfully for applied for making $\mathrm{ZnO}$ gas sensors with great potential for achieving high deposition rates at low deposition temperatures, large-scale production and low cost.
\end{abstract}

Keywords: gas sensor; aerosol deposition; carbon monoxide; zinc oxide

\section{Introduction}

A device capable of mimicking the olfactory discrimination mechanism is useful to many industries, not only for the detection of particular gases, but also for the quality control evaluation of mixtures in the food and beverage industries and for environmental monitoring. Gas sensors are widely used to detect and control a variety of harmful gases, thereby protecting both the atmospheric environment and human welfare. Semiconducting metal oxides have been extensively used as sensing materials; resistance changes in oxide-based semiconductor gas sensors are used to monitor reducing, 
toxic and inflammable gases, such as $\mathrm{NH}_{3}, \mathrm{NO}_{2}, \mathrm{H}_{2}$ and $\mathrm{CO}$. Zinc oxide $(\mathrm{ZnO})$ is a well-known functional n-type semiconductor of the II-VI group, a technologically-important, low-cost and environmentally-friendly semiconductor material, and one of the most promising candidates for detecting various gases. This semiconductor has several favorable properties, including good transparency, high electron mobility, wide bandgap, and strong room-temperature luminescence. Furthermore, $\mathrm{ZnO}$ is a unique material possessing such properties as semiconductivity, piezoelectricity and pyroelectricity. Because of its versatility, wide-band-gap wurtzite phase $\mathrm{ZnO}$ has been used in applications such as blue and ultraviolet light emitters, transparent electrodes in liquid crystal displays, solar cell windows, gas sensors, photovoltaic devices, light-emitting diodes, thin-film transistors, pyroelectric sensors, surface acoustic wave (SAW) devices and film bulk acoustic resonators (FBARs). $\mathrm{ZnO}$ has been extensively used as a gas-sensing material due to its high conduction electron mobility and good chemical and thermal stability when subjected to the operating conditions required in sensors. The sensing mechanism of $\mathrm{ZnO}$ is a surface-controlled type, in which the grain size, defects and oxygen-adsorption quantities play important roles in sensing response. It is obvious that the sensitivity and the response time of $\mathrm{ZnO}$-based sensors strongly depend on their size, specific surface area and morphology [1-4]. Moreover, gas sensors based on $\mathrm{ZnO}$ nanobelts synthesized by $\mathrm{RF}$ sputtering had been investigated with a view to sensing $\mathrm{H}_{2}, \mathrm{NO}_{2}$ and hydrocarbon at different operating temperatures [5]. A gas sensor was fabricated from the as-prepared $\mathrm{ZnO}$ hollow spheres and tested to different concentrations of $\mathrm{NH}_{3}$ and $\mathrm{NO}_{2}$ at different operating temperatures [6]. The results showed that the $\mathrm{ZnO}$ hollow-sphere sensor exhibited extremely different sensing behaviors to $\mathrm{NH}_{3}$ and $\mathrm{NO}_{2}$. A zinc oxide nanorod-based surface acoustic wave sensor for hydrogen $\left(\mathrm{H}_{2}\right)$ gas has been developed and investigated [7]. The $\mathrm{ZnO}$ nanorods were deposited onto a layered $\mathrm{ZnO} / 64^{\circ} \mathrm{YX}$ $\mathrm{LiNbO}_{3}$ substrate using a liquid solution method. The study showed that the sensor responded with highest frequency shift at $265{ }^{\circ} \mathrm{C}$. Furthermore, electronically contacted nanorods or nanotube arrays were used as gas sensors, an adsorbate modified either the impedance or the Fermi level of the array, enabling detection [8]. The arrays demonstrated the I-V curves of a Schottky diode that was formed using a metal-semiconductor junction with rectifying characteristics. The study showed that nanostructured Schottky diodes had a functionally different response, characteristic of the large electric field induced by the size scale of the array.

$\mathrm{ZnO}$ films have been synthesized by numerous methods, such as metal organic chemical vapor deposition, molecular beam epitaxy, magnetron sputtering, pulsed laser deposition, microwave-assisted hydrothermal processes, atomic layer deposition, spray pyrolysis, filtered cathodic vacuum arc technique, sol-gel process aerosol, and liquid-phase deposition technique [9-16]. Because nanostructures with high surface area and surface accessibility can significantly improve gas sensing properties, in this study an aerosol deposition (AD) process was used to grow porous $\mathrm{ZnO}$ films with a high surface-to-volume ratio for accelerating the processes and applications of the film to gas sensors. Moreover, the gas sensor was focused on the detection of carbon monoxide (CO), as $\mathrm{CO}$ gas is one of the most dangerous gases formed whenever incomplete combustion of carbonaceous products occurs, typically in automobile exhausts, forest fires and house fires. The AD method is based on impact adhesion of ultra-fine particles for forming and micro-pattering ceramic layers. It is a form of the gas deposition method or jet printing method without requiring vaporization of materials. In the $\mathrm{AD}$, ceramic films are prepared by ejecting an aerosol mixture of ultra-fine ceramic particles and gas from 
the nozzle onto substrates. During the AD operation, submicron ceramic particles are accelerated by gas flow in the nozzle up to a velocity of several hundred meters per second as they are sprayed onto substrates. The AD provides many advantages for producing films in the range of $1 \sim 100 \mu \mathrm{m}$ thickness with a high deposition rate, low deposition temperature, large-scale production and low cost $[17,18]$. Moreover, the AD method can achieve fine patterning $[19,20]$ and fabricate a dense structure through the reduction of crystallite size by fracture or plastic deformation at room temperature $[17,18]$.

In the present study, an attempt was made to deposit a porous $\mathrm{ZnO}$ film with a high surface-to-volume ratio onto silicon substrates for intended use as a $\mathrm{CO}$ gas sensor. This was done using the $\mathrm{AD}$ rapid process to accelerate the deposition process of the $\mathrm{ZnO}$ film for its application as a gas sensor.

\section{Experimental Procedure}

\subsection{Deposition of Porous $\mathrm{ZnO}$ Films}

The AD apparatus was comprised of two vacuum chambers connected by a gas pipe. The first chamber acted as the deposition chamber for the formation of films; it included a nozzle, a motion platform and a substrate with its heating system. The chamber was evacuated during the deposition process using a rotary vacuum pump with a dust collection system. The second chamber acted as the aerosol chamber to generate ceramic aerosol; it held a carrier gas system, a filter and a vibration system for mixing the ceramic powder and the carrier gas. The ceramic aerosol in the aerosol chamber was delivered to the deposition chamber due to the pressure difference between the two chambers. The ceramic powder flowed through a nozzle and was deposited onto the substrates. The velocities of the ceramic aerosol were controlled by a mass flow controller. The schematic diagram of the AD apparatus is shown in Figure 1. Table 1 shows the deposition parameters used for the AD method.

Figure 1. Schematic diagram of the aerosol deposition apparatus.

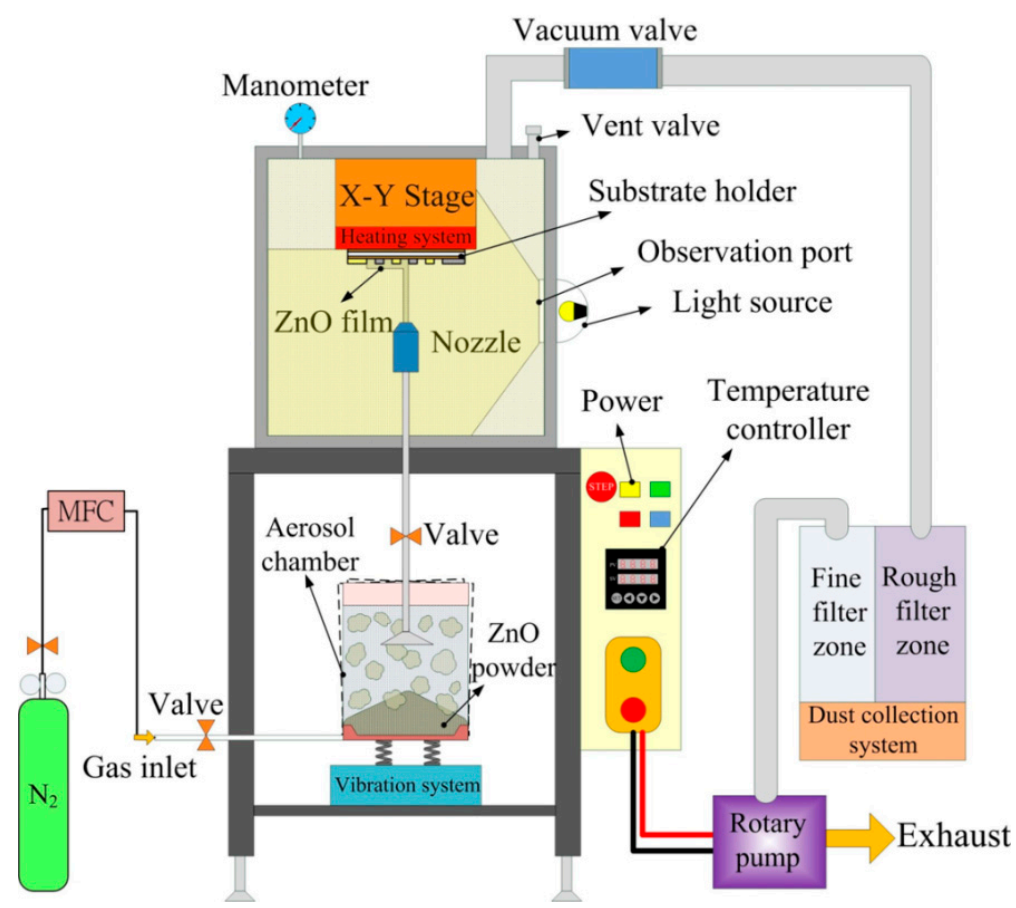


Table 1. Deposition parameters for AD.

\begin{tabular}{cc}
\hline Item & Data \\
\hline Starting powder & $\mathrm{ZnO}(530 \mathrm{~nm}$ in average diameter $)$ \\
Pressure difference between & $140($ Torr $)$ \\
deposition and aerosol chambers & Nitrogen \\
Carrier gas & $3(\mathrm{~L} / \mathrm{min})$ \\
Consumption of carrier gas & $0.4 \times 10(\mathrm{~mm} \times \mathrm{mm})$ \\
Orifice size of nozzle & $25\left({ }^{\circ} \mathrm{C}\right)$ \\
Substrate temperature & $70 \times 70(\mathrm{~mm} \times \mathrm{mm})$ \\
Deposition area & $5(\mathrm{~mm})$ \\
Distance between nozzle and substrate & $10(\mathrm{~mm} / \mathrm{s})$ \\
Scanning rate & $8.2(\mathrm{~nm} / \mathrm{s})$ \\
Deposition rate &
\end{tabular}

Table 2. Geometry and material properties of $\mathrm{ZnO}$ powder.

\begin{tabular}{cc}
\hline Item & Data \\
\hline Appearance & White powder \\
Density & $5.61 \mathrm{~g} / \mathrm{cm}^{3}$ \\
Specific surface area & $17 \mathrm{~m}^{2} / \mathrm{g}$ \\
Particle form & Sheet \\
Particle size & $300 \mathrm{~nm}$ (Diameter) $\times 20 \mathrm{~nm}$ (Thickness) \\
\hline
\end{tabular}

Table 3. Process parameters for $\mathrm{ZnO}$ film treated by laser annealing.

\begin{tabular}{cc}
\hline Item & Data \\
\hline Laser type & Continuous-wave $\mathrm{CO}_{2}$ laser \\
Laser power & $25(\mathrm{~W})$ \\
Movement velocity of laser head & $1.4(\mathrm{~mm} / \mathrm{s})$ \\
Distance between substrates and laser head & $40(\mathrm{~mm})$ \\
Ambient gas & Nitrogen \\
Flow rate of ambient gas & $3(\mathrm{~L} / \mathrm{min})$ \\
Laser spot & $2 \mathrm{~mm}$ (diameter) \\
\hline
\end{tabular}

The ZnO powder was provided by Top Nano Technology Co. Ltd., of New Taipei, Taiwan. The geometry and material properties of the starting $\mathrm{ZnO}$ powder are shown in Table 2. High moisture content in the ceramic powder is responsible for a reduction in film quality because agglomerated particles serve as a cushion to absorb kinetic energy when powders impact against substrates, resulting in the formation of compacted powders. Hence, a pre-treatment of the $\mathrm{ZnO}$ starting powder was carried out to improve the $\mathrm{ZnO}$ film quality by applying heat at $150{ }^{\circ} \mathrm{C}$ for $1 \mathrm{~h}$ using an oven. A $\mathrm{ZnO}$ film with a thickness of about $1 \mu \mathrm{m}$ was deposited onto the silicon substrate by the $\mathrm{AD}$ at room temperature, employing various process parameters. Furthermore, the laser annealing system (LEE-25, Laser Life, Taipei, Taiwan), using continuous-wave $\mathrm{CO}_{2}$ laser irradiation with a wavelength of $10.6 \mu \mathrm{m}$, power of $25 \mathrm{~W}$ and beam diameter of $2 \mathrm{~mm}$, was adopted for the $\mathrm{ZnO}$ film annealing in a $\mathrm{N}_{2}$ atmosphere. The laser annealing parameters comprised the movement velocity of the laser head in the X-Y plane, distance between substrates and laser head, laser power adjustment, ambient gas and flow rate, as 
shown in Table 3. The thickness of the $\mathrm{ZnO}$ films was further probed by a surface analyzer (ET-4000AK, Kosaka, Tokyo, Japan). The morphological properties were examined using scanning electron microscopy (SEM).

\subsection{Fabrication of $\mathrm{ZnO}$ Gas Sensors}

The $\mathrm{ZnO}$ gas sensor is comprised of a substrate with a silicon nitride layer, a heater (Pt/Ti), a pair of comb-like electrodes and a sensing porous $\mathrm{ZnO}$ film, as shown schematically in Figure 2 . The width of the signal electrodes and heater was $50 \mu \mathrm{m}$, with a distance of $30 \mu \mathrm{m}$ maintained between the electrodes and the heater.

Figure 2. Schematic diagram of the $\mathrm{ZnO}$ gas sensor (unit: $\mu \mathrm{m}$ ).

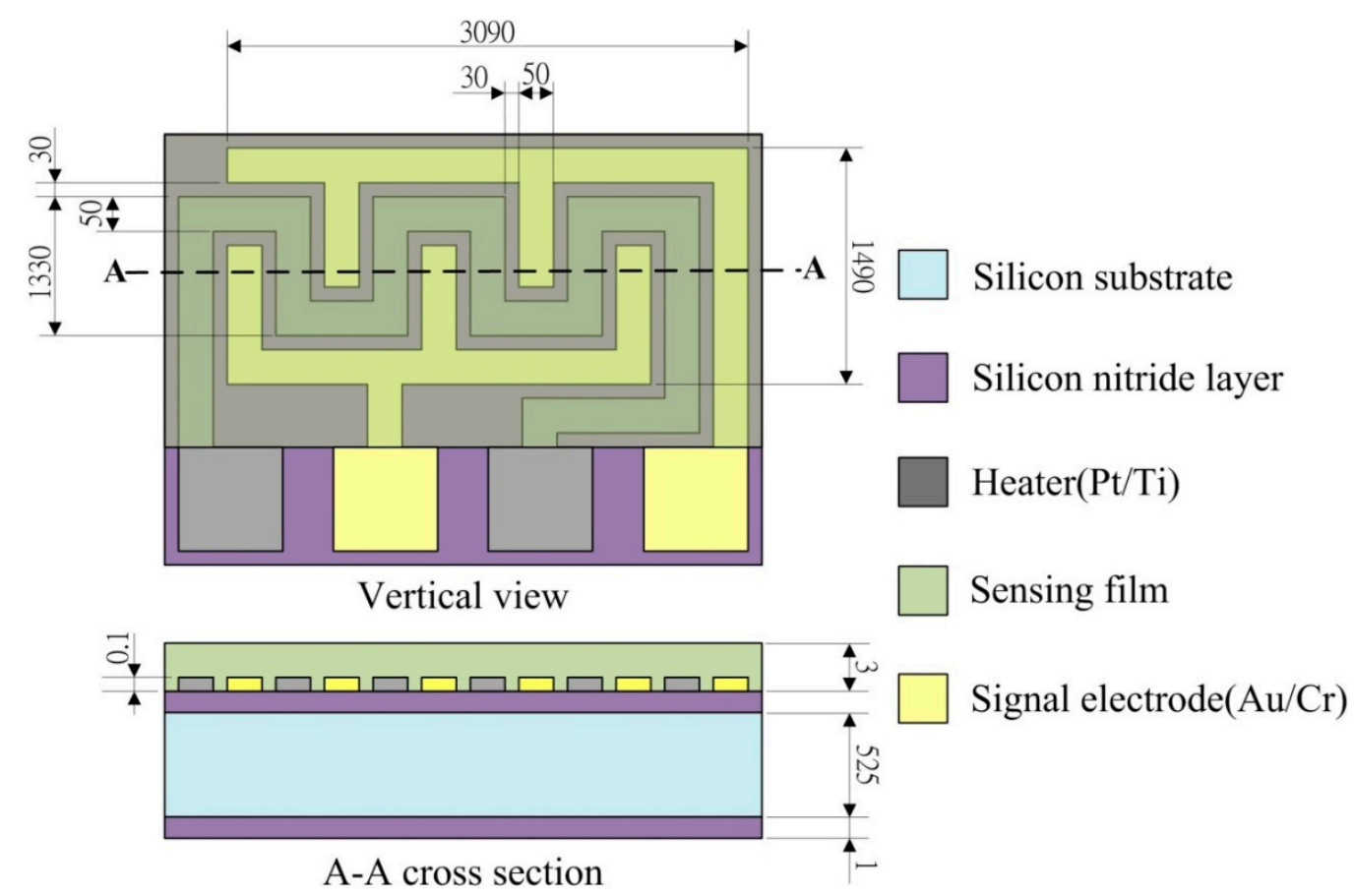

The process flow of the $\mathrm{ZnO}$ gas sensor was divided into several steps, as follows. A silicon wafer with specifications of (100) p-type, double-side polished and a resistivity of 1-10 O-cm, was used as the substrate supporting the $\mathrm{ZnO}$ gas sensor. As shown in Figure 3a, a low-stress silicon nitride layer with a thickness of $1 \mu \mathrm{m}$ was deposited on both sides of the substrate by LPCVD to be used as a thermal and electrical isolation layer. The pair of comb-like electrodes were deposited on the substrate by electron beam (E-beam) evaporation (as shown in Figure $3 \mathrm{~b}$ ) and patterned by photolithography (as shown in Figure 3c) with wet etching (as shown in Figure 3d). These electrodes comprised a $100 \mathrm{~nm}$-thick gold layer and a $10 \mathrm{~nm}$-thick chromium adhesion layer. In addition, the heater was patterned by photolithography (as shown in Figure 3e) and deposited on the substrate by electron beam (E-beam) evaporation (as shown in Figure 3f). A lift-off process was used to achieve the heater process, as shown in Figure $3 \mathrm{~g}$. The heater comprised a $100 \mathrm{~nm}$-thick platinum layer and a $10 \mathrm{~nm}$-thick titanium adhesion layer. The next step was to deposit the $\mathrm{ZnO}$ films about $1 \mu \mathrm{m}$ in thickness by the AD and pattern these using the shadow mask method (as shown in Figure 3h). The ZnO film promoted by 
laser annealing ensued, as shown in Figure 3i. The fabricated $\mathrm{ZnO}$ gas sensor is shown in Figure 4. The porous $\mathrm{ZnO}$ architectures produced by $\mathrm{AD}$ were characterized by SEM, as depicted in Figure 5 .

Figure 3. Process flow for the $\mathrm{ZnO}$ gas sensor.

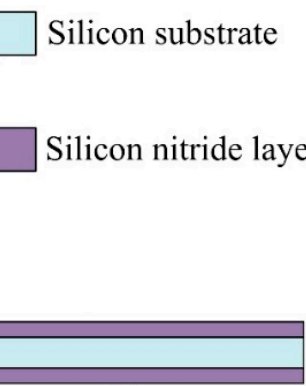

(a)

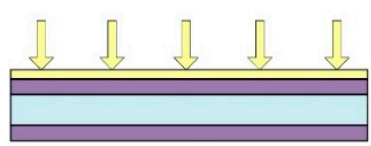

(b)

Photolithography process

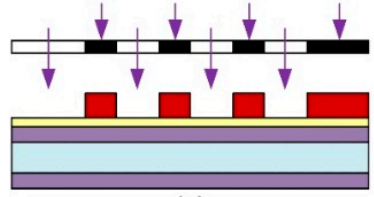

(c)
Photoresistor

Heater(Pt/Ti)

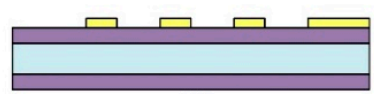

(d)

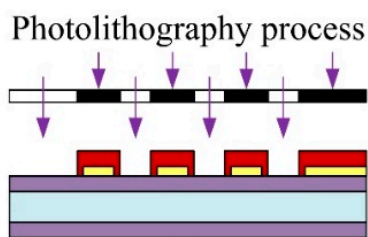

(e)

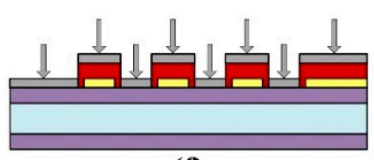

(f)
Sensing film

Signal electrode $(\mathrm{Au} / \mathrm{Cr})$

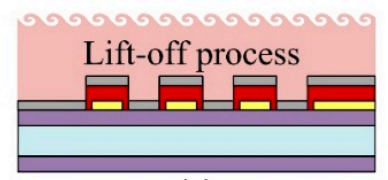

(g)

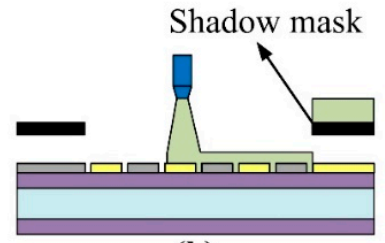

(h)

Ambience of nitrogen

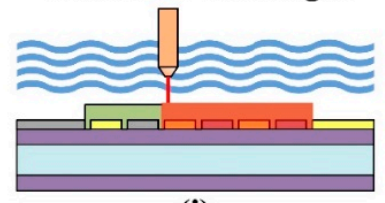

(i)

Figure 4. Fabricated $\mathrm{ZnO}$ gas sensor.

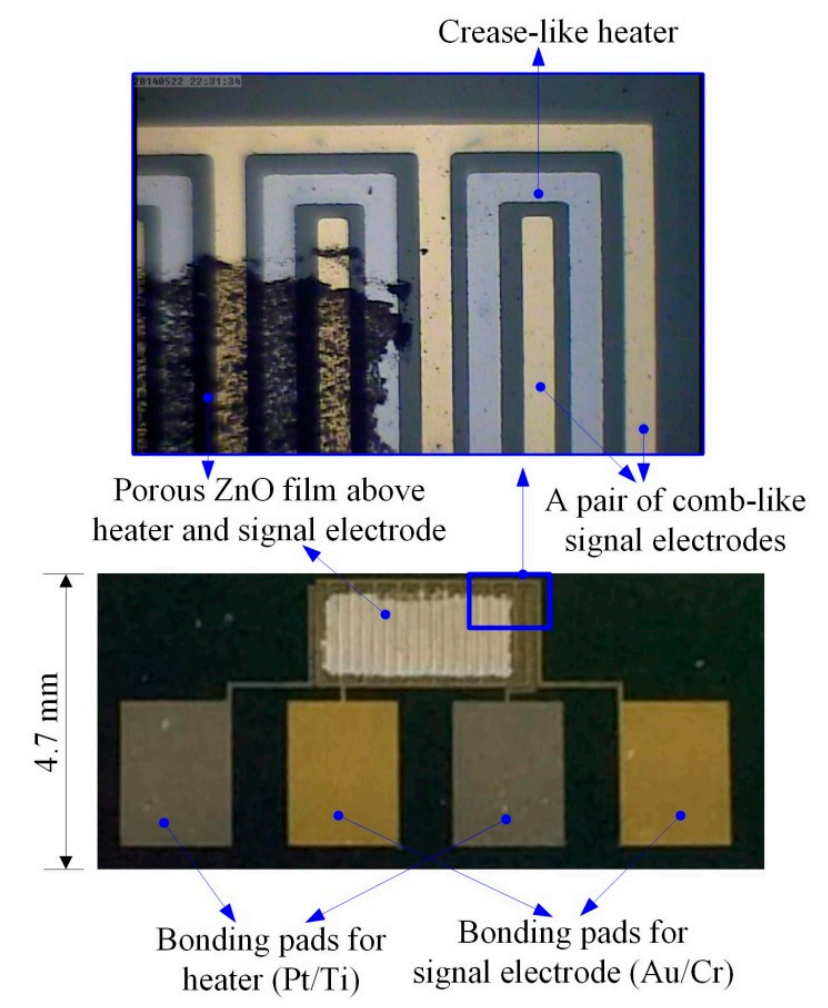


Figure 5. SEM images of the $\mathrm{ZnO}$ film deposited by $\mathrm{AD}$ with magnification of (a) $10,000 \times$ and (b) $50,000 \times$.

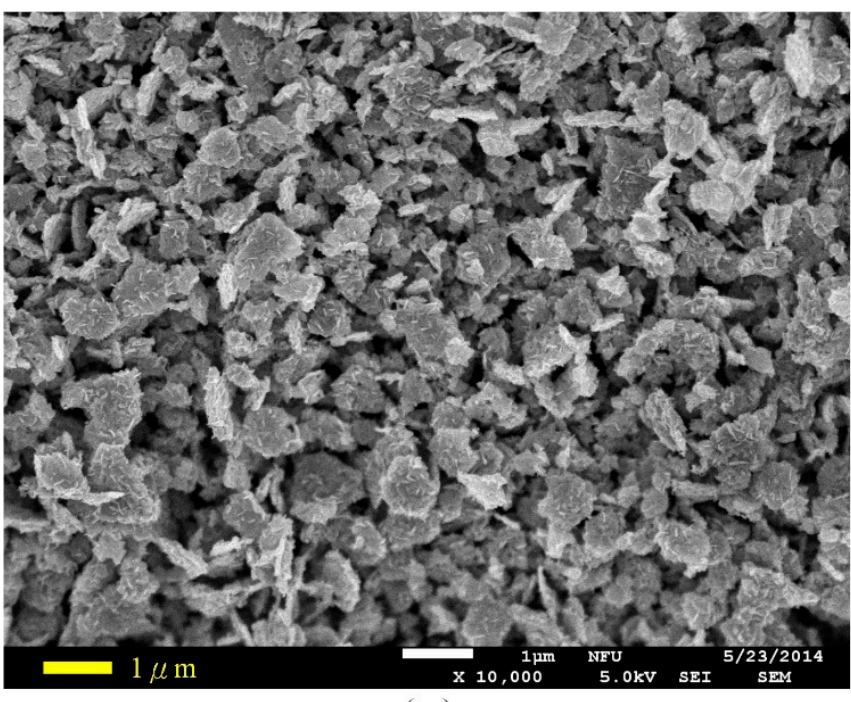

( a )

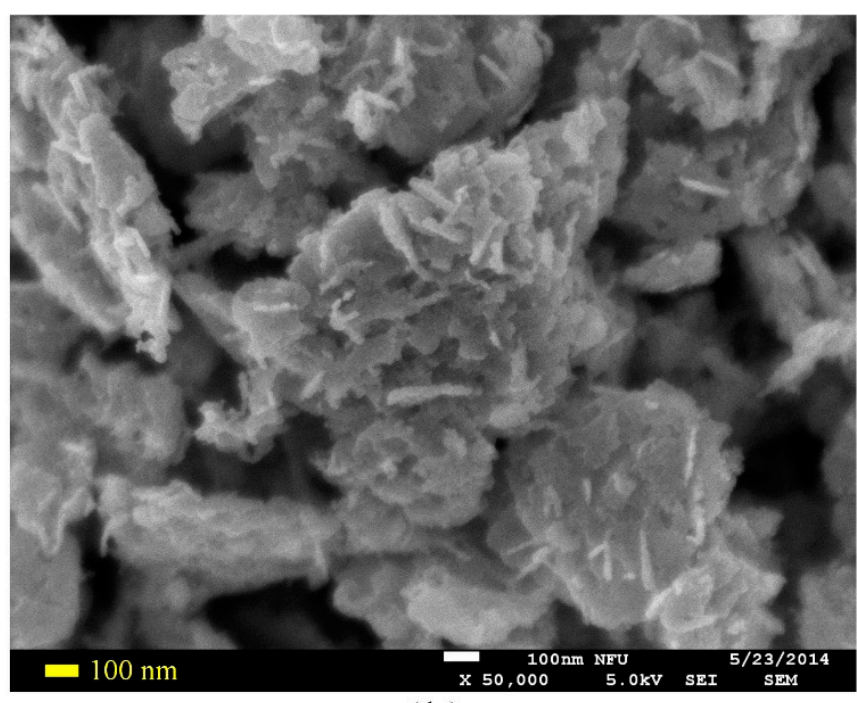

(b)

Figure 6. Schematic diagram of a computer-controlled gas sensing characterization system.

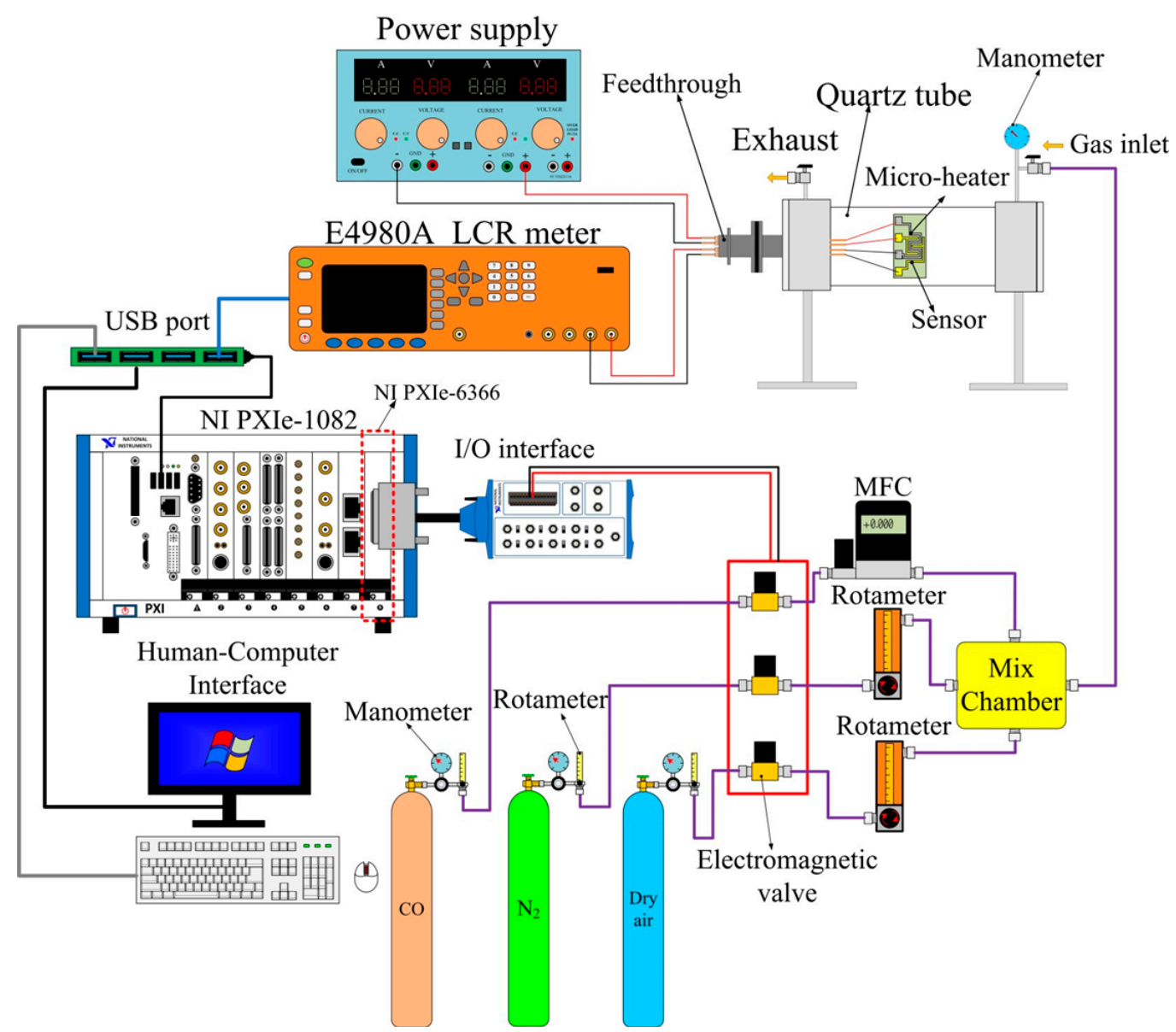

\subsection{Gas Sensing Property Measurements}

The electrical and $\mathrm{CO}$ gas-sensing properties of the fabricated gas-sensing elements were measured by a LCR meter attached to a pair of comb-like electrodes. An Agilent E4980A system 
formed a computer-controlled gas-sensing characterization system using a flow-through method, shown schematically in Figure 6. This automatic measurement of the gas sensing system was achieved primarily using an NI LabVIEW system consisting of a NI PXIe-1082 case, a NI PXIe-8135 controller, a NI PXIe-6366 data acquisition card and NI LabVIEW 2012 software. The gas sensors were placed in a sealed quartz tube acting as an airtight chamber possessing an inlet, an outlet and electrical feed-through. Carrier gas (dry air) and target gas $\left(\mathrm{CO}\right.$ with $\left.\mathrm{N}_{2}\right)$ were loaded into the sealed chamber through the inlet port while the gases automatically exited the outlet port due to the difference in pressure between the interior and exterior of the chamber. During the whole measurement, dry air was continuously introduced into the chamber at a flow rate of $500 \mathrm{sccm}$. The target gas (CO) at an initial concentration of $5000 \mathrm{ppm}$ with nitrogen balance and coordination was further diluted in dry air (flow rate of $500 \mathrm{sccm}$ ) for controlling the $\mathrm{CO}$ gas concentration. The operating temperature was controlled using a micro-heater consisting of platinum and titanium layers integrated within the $\mathrm{ZnO}$ gas sensor.

\section{Results and Discussion}

The phase and structural analysis of the aerosol deposited $\mathrm{ZnO}$ films was carried out by XRD and is shown in Figure 7. The XRD pattern exhibited typical peaks at $2 \theta=31.80^{\circ}, 34.60^{\circ}, 36.20^{\circ}, 47.50^{\circ}$, $56.60^{\circ}, 62.90^{\circ}$ and $67.90^{\circ}$ belonging to the reflection of (100), (002), (101), (102), (110), (103) and (112) of the wurtzite hexagonal $\mathrm{ZnO}$, respectively, with the lattice constants of $\mathrm{a}=0.325 \mathrm{~nm}$ and $\mathrm{c}=0.521 \mathrm{~nm}$ (JCPDS card, No. 36-1451). The X-ray diffractogram indicated the growth of the $\mathrm{ZnO}$ film treated by laser annealing along the seven planes of orientations (100), (002), (101), (102), (110), (103) and (112). Though prominent growth occurred along (100), (002) and (101), the most preferential growth was observed along the (002) plane with the FWHM of $0.26^{\circ}$.

Figure 7. The XRD pattern of the aerosol deposited $\mathrm{ZnO}$ film.

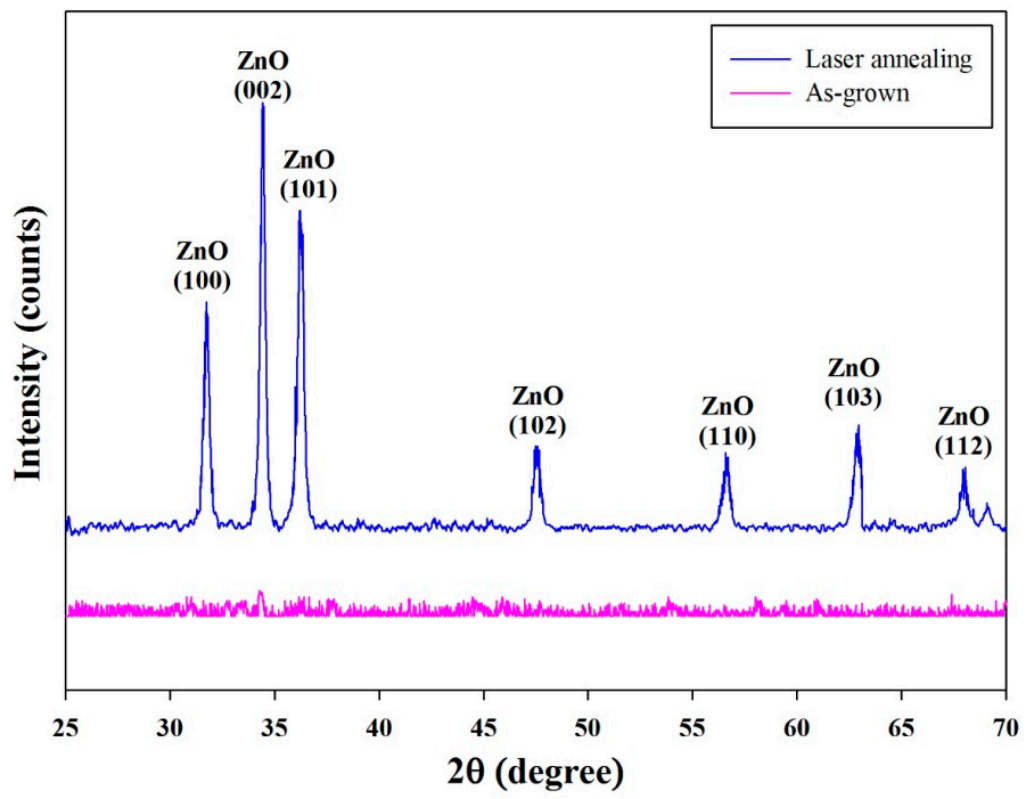

The $\mathrm{CO}$ gas-sensing properties of the porous $\mathrm{ZnO}$ film gas sensors were measured by using various $\mathrm{CO}$ gas concentrations. The gas-sensing mechanism of the semiconducting metal oxide gas sensors is based on variations in electrical resistance or conductance due to gas adsorption and desorption on the 
sensor surface. When the $\mathrm{ZnO}$ gas sensors are exposed to air, oxygen molecules from the ambient air adsorb on the exposed $\mathrm{ZnO}$ surface to form chemisorbed oxygen anions; $\left(\mathrm{O}_{2}^{-}, \mathrm{O}^{-}\right.$or $\mathrm{O}^{2-}$, depending on the operating temperature) by capturing electrons from the $\mathrm{ZnO}$ conduction band. This results in the formation of a depletion layer, known as the space charge layer, on the surface of the $\mathrm{ZnO}$ sensing material. This induces an increase in the resistance of the sensing materials. The reactions under various operating temperatures can be described as follows:

$$
\begin{gathered}
\mathrm{O}_{2}+\mathrm{e}^{-} \rightarrow \mathrm{O}_{2}^{-} \\
\mathrm{O}_{2}+2 \mathrm{e}^{-} \rightarrow 20^{-} \\
\mathrm{O}_{2}+4 \mathrm{e}^{-} \rightarrow 20^{2-}
\end{gathered}
$$

When the $\mathrm{ZnO}$ gas sensors are exposed in a $\mathrm{CO}$ environment at a moderate temperature, the adsorbed $\mathrm{CO}$ gas reacts with the chemisorbed oxygen anions on the $\mathrm{ZnO}$ surface, resulting in $\mathrm{CO}_{2}$ molecules and the release of electrons back into the conduction band. This leads to an increase in the concentration of electrons. The resistivity of the $\mathrm{ZnO}$ films decreases for detecting the $\mathrm{CO}$ gas. The reactions under various operating temperatures can be described as follows:

$$
\begin{gathered}
2 \mathrm{CO}+\mathrm{O}_{2}^{-} \rightarrow 2 \mathrm{CO}_{2}+\mathrm{e}^{-} \\
\mathrm{CO}+\mathrm{O}^{-} \rightarrow \mathrm{CO}_{2}+\mathrm{e}^{-} \\
\mathrm{CO}+\mathrm{O}^{2-} \rightarrow \mathrm{CO}_{2}+2 \mathrm{e}^{-}
\end{gathered}
$$

Because $\mathrm{ZnO}$ is a low-conductive semiconductor material, oxygen ion sorption and the transfer of electrons is not possible at room temperature. The dynamic resistance transients with various tested temperatures and $\mathrm{CO}$ concentrations are depicted in Figure 8. The initial resistance of the $\mathrm{ZnO}$ gas sensor in dry air was high, whereas its resistance decreased abruptly when it was exposed to CO gas. The resistance of the $\mathrm{ZnO}$ gas sensor decreased after each $\mathrm{CO}$ gas injection cycle. This exhibits n-type semiconducting behavior of the $\mathrm{ZnO}$ material, and its response and recovery process can be established by comparing the resistance of the $\mathrm{ZnO}$ nano-architectures in different ambiences. $\mathrm{CO}$ is a well-known reducing gas that can provide electrons to n-type $\mathrm{ZnO}$ semiconducting nano-architectures. The resistance variation between the injection cycles of $\mathrm{CO}$ and dry air increased with increasing test temperatures and $\mathrm{CO}$ concentrations. Moreover, the lower initial resistance at higher temperatures was also ascribed to the semiconducting property of the $\mathrm{ZnO}$ material. It was clearly seen that the response characteristics of the sensor depended on the operating temperature. The sensitivity $\left(\mathrm{S}_{\mathrm{CO}}\right)$ of the porous $\mathrm{ZnO}$ gas sensors is defined as a ratio of the change in resistance between samples exposed in dry air and in $\mathrm{CO}$ gas:

$$
\mathrm{S}_{\mathrm{CO}}=\left(\mathrm{R}_{\mathrm{a}}-\mathrm{R}_{\mathrm{CO}}\right) / \mathrm{R}_{\mathrm{a}}
$$

where $R_{a}$ is the resistance of the samples measured in air, and $R_{C O}$ is the resistance of the samples measured in $\mathrm{CO}$ gas. The resistance is measured between the pair of comb-like electrodes via the $\mathrm{ZnO}$ film deposited by the AD method. Figure 9 shows the relationship between $\mathrm{CO}$ concentrations and sensitivity observed for the gas sensors at various operating temperatures. The sensitivity of the sensors increased as $\mathrm{CO}$ concentrations and operating temperatures increased. It is well known that the sensitivity of the sensor based on sensing oxides was mainly determined by the interactions between 
the target gas and the sensing surface. Furthermore, it can ensure that the surface area of the sensing materials is greater, and the stronger interaction and the higher response can be expected [4]. The $\mathrm{ZnO}$ nanoarchitectures fabricated by the AD are shown in Figure 5; with interlaced-connected network, they maintained the high surface area and efficiently avoided the agglomerated configuration, resulting in an excellent response. This architecture presented a stacked structure with $\mathrm{ZnO}$ nanosheets. Moreover, some nanoprotrusions were attached onto the $\mathrm{ZnO}$ nanosheets, and they were produced by laser annealing to increase the sensing surface.

Figure 8. Variation in resistance of $\mathrm{ZnO}$ gas sensors during the cycles of $\mathrm{CO}$ injection and termination under various operating temperatures, (a) $110{ }^{\circ} \mathrm{C}$; (b) $140{ }^{\circ} \mathrm{C}$; (c) $160{ }^{\circ} \mathrm{C}$; (d) $180{ }^{\circ} \mathrm{C}$.
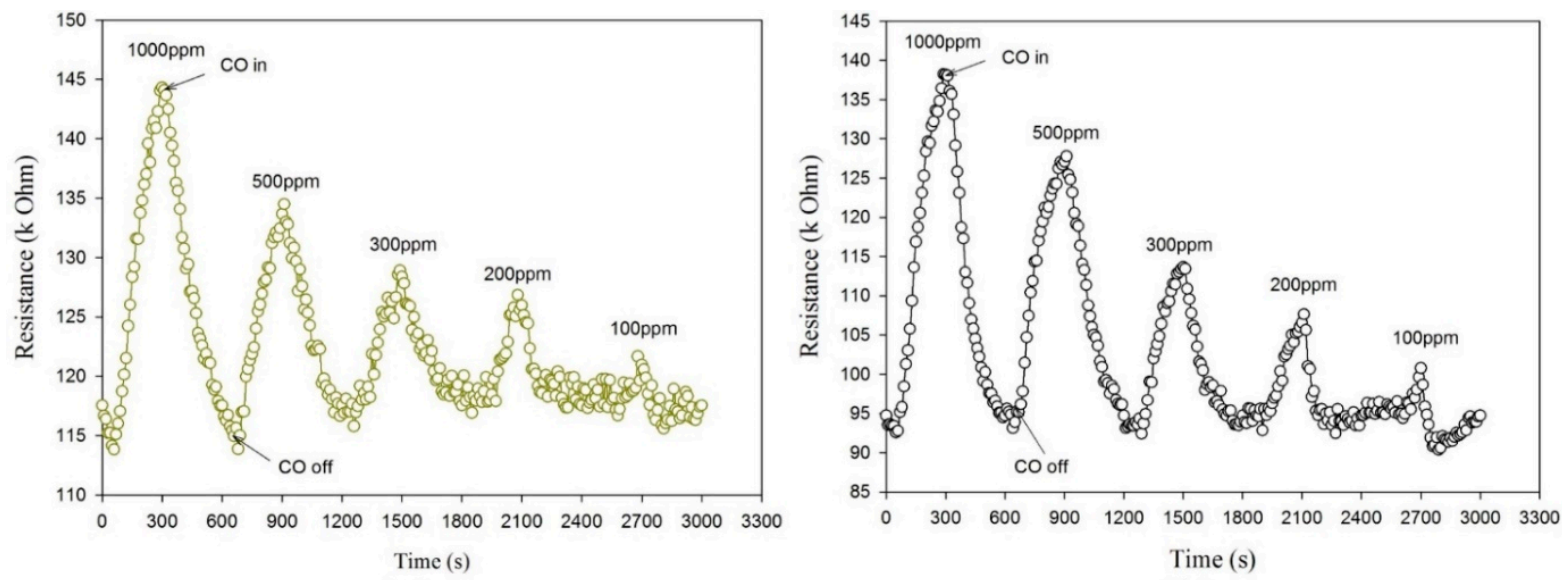

( a )

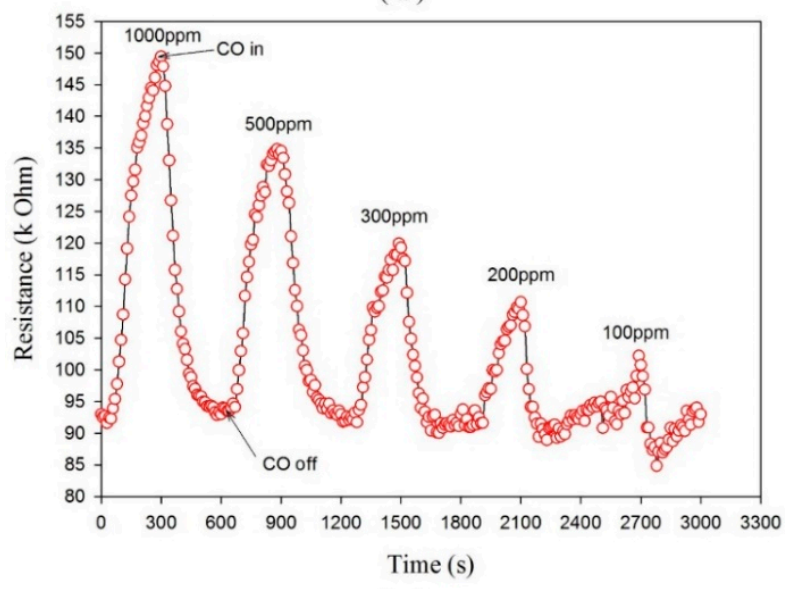

(c)

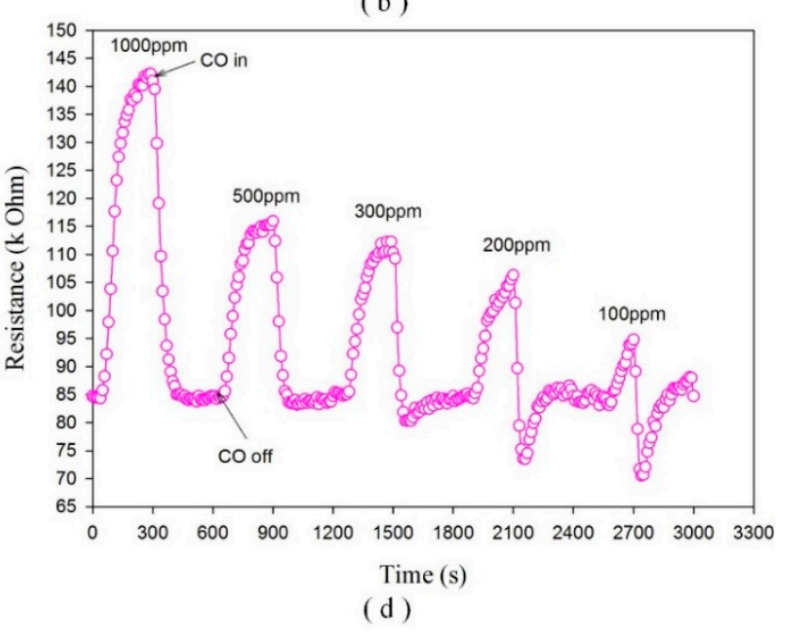

The response and recovery time are important characteristics for appraising gas sensors, and they determined the surface accessibility of the sensing framework. Furthermore, the response time included the gas diffusion toward the sensing surface for reacting with chemisorbed oxygen ions, and the subsequent re-oxidation process of the sensing surface to yield oxygen species. The response and recovery time were defined as the time required for the gas sensor to achieve $90 \%$ of the total resistance change in the case adsorption and desorption, respectively. The response and the recovery time were related to operating temperatures; they shrank to increase the operating temperature. Figure 10 shows the relationship between $\mathrm{CO}$ concentrations, and the response and recovery time for the gas sensors at a higher operating temperature of $180{ }^{\circ} \mathrm{C}$. The response time was smaller than the 
recovery time at each $\mathrm{CO}$ concentration. This was effective for practical application because the gas sensors generally readied in an ambiance of dry air. Therefore, a short response time was useful for detecting the variation of CO concentrations. The response time ranged from $24 \mathrm{~s}$ to $45 \mathrm{~s}$, whereas the recovery time ranged from $55 \mathrm{~s}$ to $110 \mathrm{~s}$ under CO concentrations varying from $1000 \mathrm{ppm}$ to $100 \mathrm{ppm}$. Furthermore, the $\mathrm{ZnO}$ gas sensor for $\mathrm{CO}$ gas-sensing properties was estimated by a circulation of $\mathrm{CO}$ injection about $5 \mathrm{~min}$ and an air ambiance about $5 \mathrm{~min}$. The resistance curve was like to a triangle shape while the $\mathrm{ZnO}$ gas sensor worked at the lower operating temperature. This meant that the total resistance change of the $\mathrm{ZnO}$ film needed more time. Although the response and recovery time for observing the total resistance change of the $\mathrm{ZnO}$ film increased at the lower operating temperature, the sensitivity of the $\mathrm{ZnO}$ gas sensor at the lower operating temperature was still ponderable.

Figure 9. Relationship between CO concentrations and sensitivity of the gas sensors under various operating temperatures.

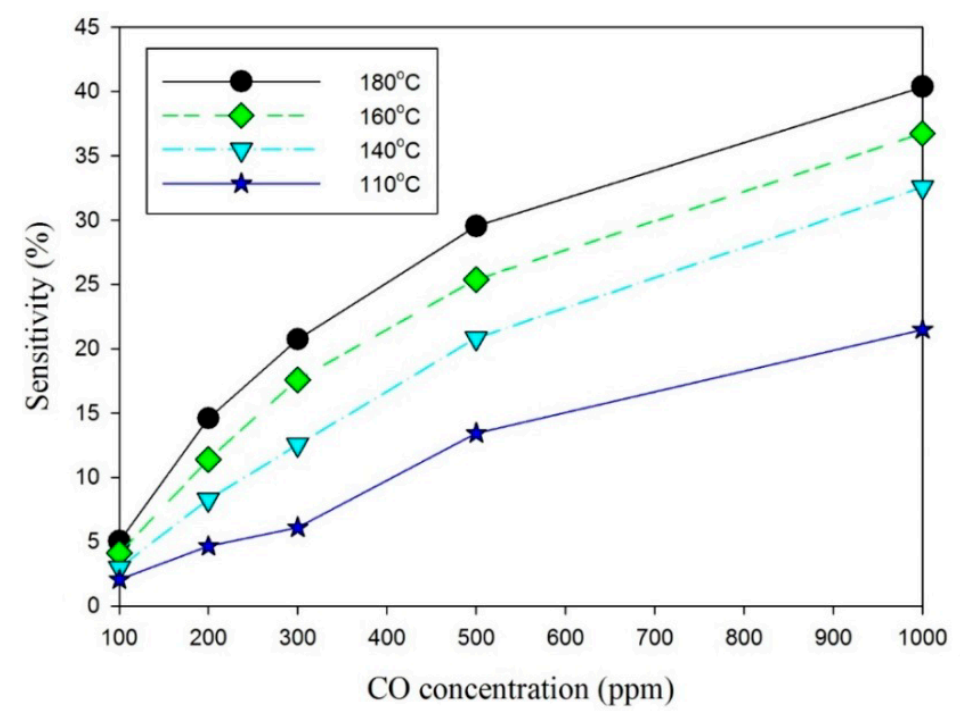

Figure 10. Relationship between $\mathrm{CO}$ concentrations, and the response and the recovery time for the gas sensors at a higher operating temperature of $180^{\circ} \mathrm{C}$.

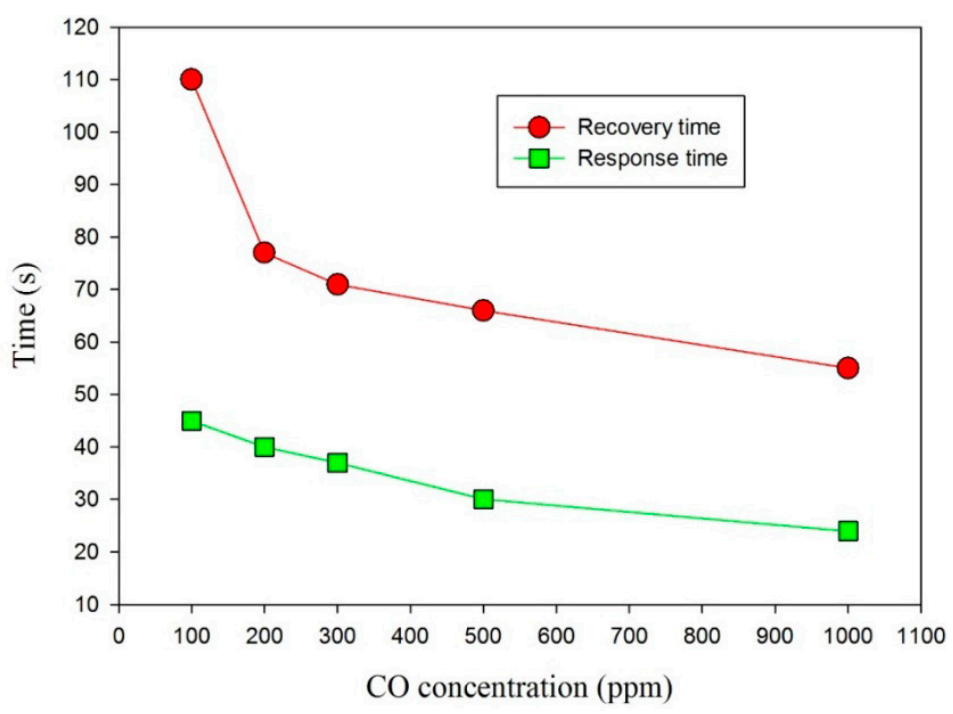


The possible model for clarifying the gas-sensing mechanism of the nanorods' film gas sensors had been demonstrated [21]. The three types of junctions: point-junction, cross-junction and block-junction formed the potential barriers and blocked electrons percolating in $\mathrm{ZnO}$ nanorods network. Moreover, the potential barrier of the point-junction formed by the two depletion layers of the two contact nanorods was more significantly modified upon exposure to the target gas compared with that of the block and the cross-junction. In the present study, the $\mathrm{ZnO}$ nanoarchitecture deposited by the AD was a porous $\mathrm{ZnO}$ film with a stacked structure. The randomly-stacked $\mathrm{ZnO}$ film possessed a larger surface area for reacting to $\mathrm{CO}$ gas and absorbing more $\mathrm{CO}$ gas. Furthermore, the proposed $\mathrm{ZnO}$ film presented more junctions between nanosheets for enhancing the resistance variation and increasing the surface accessibility. Therefore, the $\mathrm{ZnO}$ film grown by the $\mathrm{AD}$ using pure $\mathrm{ZnO}$ powder results in a low-cost, rapid, convenient, large-scale and simple process for fabricating gas-sensing devices.

\section{Conclusions}

The rapid $\mathrm{AD}$ process is proposed for application to gas sensors. This may minimize production costs, reduce the necessity of additional post-assembly processes and diminish the scope of fabrication processes. Zinc oxide $(\mathrm{ZnO})$ is an environmentally-friendly material, which can be used in producing green products and devices. The $\mathrm{AD}$ process was successfully used to accelerate the application of $\mathrm{ZnO}$ films onto $\mathrm{CO}$ gas-sensing devices. The resulting $\mathrm{CO}$ gas sensor demonstrated improved performance, yet it can still be fabricated more quickly and at a lower cost.

\section{Acknowledgments}

The authors are thankful for the financial support from the National Science Council of Taiwan through Grant No. NSC 102-2221-E-150-037, and the experimental support from the Micro-Device Laboratory at the National Formosa University. The contributions of Pei-Zen Chang and Xuan-Yu Wang in the technique support are particularly acknowledged.

\section{Author Contributions}

Li-Siang Luo was involved in the data collection and experimental work under supervision of Chun-Ching Hsiao who carefully edited the paper, provided technical support and guidance, and directly contributed the results of this paper.

\section{Conflicts of Interest}

The authors declare no conflict of interest.

\section{References}

1. Hung, N.L.; Kim, H.; Hong, S.K.; Kim, D. Enhancement of $\mathrm{CO}$ gas sensing properties in $\mathrm{ZnO}$ thin films deposited on self-assembled Au nanodots. Sens. Actuators B Chem. 2010, 151, 127-132.

2. Rai, P.; Kim, Y.S.; Song, H.M.; Song, M.K.; Yu, Y.T. The role of gold catalyst on the sensing behavior of $\mathrm{ZnO}$ nanorods for $\mathrm{CO}$ and $\mathrm{NO}_{2}$ gases. Sens. Actuators B Chem. 2012, 165, 133-142. 
3. Joshi, R.K.; Hu, Q.; Alvi, F.; Joshi, N.; Kumar, A. Au decorated zinc oxide nanowires for CO sensing. J. Phys. Chem. 2009, 113, 16199-16202.

4. Zeng, Y.; Qiao, L.; Bing, Y.; Wen, M.; Zou, B.; Zheng, W.; Zhang, T.; Zou, G. Development of microstructure $\mathrm{CO}$ sensor based on hierarchically porous $\mathrm{ZnO}$ nanosheet thin films. Sens. Actuators B Chem. 2012, 173, 897-902.

5. Sadek, A.Z.; Choopun, S.; Wlodarski, W.; Ippolito, S.J.; Kalantar-zadeh, K. Characterization of $\mathrm{ZnO}$ nanobelt-based gas sensor for $\mathrm{H}_{2}, \mathrm{NO}_{2}$, and hydrocarbon sensing. IEEE Sens. J. 2007, 7, 919-924.

6. Zhang, J.; Wang, S.; Wang, Y.; Xu, M.; Xia, H.; Zhang, S.; Huang, W.; Guo, X.; Wu, S. $\mathrm{ZnO}$ hollow spheres: Preparation, characterization, and gas sensing properties. Sens. Actuators B Chem. 2009, 139, 411-417.

7. Sadek, A.Z.; Wlodarski, W.; Li, Y.X.; Yu, W.; Li, X.; Yu, X.; Kalantar-zadeh, K. A ZnO nanorod based layered $\mathrm{ZnO} / 64^{\circ} \mathrm{YX} \mathrm{LiNbO}_{3} \mathrm{SAW}$ hydrogen gas sensor. Thin Solid Films 2007, 515, 8705-8708.

8. Yu, J.; Ippolito, S.J.; Wlodarski, W.; Strano, M.; Kalantar-zadeh, K. Nanorod based Schottky contact gas sensors in reversed bias condition. Nanotechnology 2010, 21, doi:10.1088/0957-4484/ 21/26/265502.

9. Breedon, M.; Rahmani, M.B.; Keshmiri, S.H.; Wlodarski, W.; Kalantar-zadeh, K. Aqueous synthesis of interconnected $\mathrm{ZnO}$ nanowires using spray pyrolysis deposited seed layers. Mater. Lett. 2010, 64, 291-294.

10. Tarwal, N.L.; Rajgure, A.V.; Inamdar, A.I.; Devan, R.S.; Kim, I.Y.; Suryavanshi, S.S.; Ma, Y.R.; Kim, J.H.; Patil, P.S. Growth of multifunctional $\mathrm{ZnO}$ thin films by spray pyrolysis technique. Sens. Actuators A Phys. 2013, 199, 67-73.

11. Campbell, J.L.; Breedon, M.; Latham, K.; Kalantar-zadeh, K. Electrowetting of superhydrophobic $\mathrm{ZnO}$ nanorods. Langmuir 2008, 24, 5091-5098.

12. Hsiao, C.C.; Huang, K.Y.; Hu, Y.C. Fabrication of a ZnO pyroelectric sensor. Sensors 2008, 8, 185-192.

13. Shieh, H.H.; Cheng, I.C.; Chen, J.Z.; Hsiao, C.C.; Lin, P.C.; Yeh, Y.H. The electromechanical characteristics of $\mathrm{ZnO}$ grown on poly(ethylene terephthalate) substrates. J. Electrochem. Soc. 2010, 157, H750-H754.

14. Yamada, A.; Sang, B.; Konagai, M. Atomic layer deposition of $\mathrm{ZnO}$ transparent conducting oxides. Appl. Surface Sci. 1997, 112, 216-222.

15. Look, D.C.; Reynolds, D.C.; Litton, C.W.; Jones, R.L.; Eason, D.B.; Cantwell, G. Characterization of homoepitaxial p-type $\mathrm{ZnO}$ grown by molecular beam epitaxy. Appl. Phys. Lett. 2002, 81, 1830-1832.

16. Mahpeykar, S.M.; Koohsorkhi, J.; Ghafoori-Fard, H. Ultra-fast microwave-assisted hydrothermal synthesis of long vertically aligned $\mathrm{ZnO}$ nanowires for dye-sensitized solar cell application. Nanotechnology 2012, 23, doi:10.1088/0957-4484/23/16/165602.

17. Akedo, J. Aerosol deposition of ceramic thick films at room temperature: Densification mechanism of ceramic layers. J. Am. Ceram. Soc. 2006, 89, 1834-1839.

18. Miyoshi, T. Preparation of full-dense $\mathrm{Pb}(\mathrm{Zr}, \mathrm{Ti}) \mathrm{O}_{3}$ ceramics by aerosol deposition. J. Am. Ceram. Soc. 2008, 91, 2098-2104. 
19. Akedo, J.; Ichiki, M.; Kikuchi, K.; Maeda, R. Jet molding system for realization of three-dimensional micro-structures. Sens. Actuators A Phys. 1998, 69, 106-112.

20. Wang, X.Y.; Lee, C.Y.; Hu, Y.C.; Shih, W.P.; Lee, C.C.; Huang, J.T.; Chang, P.Z. The Fabrication of silicon-based PZT microstructures using aerosol deposition method. J. Micromech. Microeng. 2008, 18, doi:10.1088/0960-1317/18/5/055034.

21. Khoang, N.D.; Hong, H.S.; Trung, D.D.; Duy, N.V.; Hoa, N.D.; Thinh, D.D.; Hieu, N.V. On-chip growth of wafer-scale planar-type $\mathrm{ZnO}$ nanorod sensors for effective detection of $\mathrm{CO}$ gas. Sens. Actuators B Chem. 2013, 181, 529-536.

(C) 2014 by the authors; licensee MDPI, Basel, Switzerland. This article is an open access article distributed under the terms and conditions of the Creative Commons Attribution license (http://creativecommons.org/licenses/by/3.0/). 